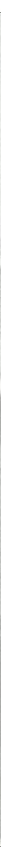

Bakgrunn: Ifølge NSFs nye strategi for eHelse, er det ønskelig at sykepleiere deltar i utviklingen av elektroniske systemer, som kan støtte arbeidsprosesser og styrke samhandling.

Hensikt: I artikkelen diskuterer vi betingelser for at systemer skal kunne bidra til dette.

Metode: Studien som beskrives artikkelen bygger på intervjuer av systemforvaltere i et norsk sykehus og observasjon av dem i arbeid. Systemforvalterne hadde helsefaglig utdannelse og de var involvert i integrering av elektronisk pasientjournal (EPJ) i klinisk arbeid.

Resultater: I starten ble EPJ brukt som en pasientjournal, men etter hvert ble avanserte funksjoner slik som «arbeidsflyt», også tatt i bruk. Med økende kompleksitet i systemet ble klinisk personell sårbar for mulige feil når det gjaldt lagring og sending av informasjon. For å unngå feilbruk fikk systemforvalterne ansvar for å utarbeide standarder for bruk. Standardiseringsarbeidet var omfattende. Det la føringer for hva klinikerne kunne gjøre, samtidig som det genererte kunnskap om arbeidsprosessene i sykehuset, systemets funksjonaliteter og bruksområder som burde standardiseres.

Konklusjon: Systemforvalterne knyttet forbindelser mellom arbeidsprosesser i sykehus og EPJ. Integrasjon av systemet skjedde gjennom slike sammenknytninger. Siden systemforvalterne har stor innflytelse på den faktiske integreringen bør de brukes strategisk i utvikling av systemer som understøtter sykepleiefaglige arbeidsprosesser og samhandling.
Facilitating integration of electronic patient record systems in clinical work

Background: The NNO's strategy of eHealth encourages nurses to participate in the development of electronic systems that facilitate work processes and interaction.

Objective: This article discusses preconditions for how systems may facilitate this.

Method: The discussion is based on interviews with system tailors and observations of their work. The system tailors were educated as healt- hcare professionals and they were central in the integration of a new electronic patient record system into clinical work.

Results: The system was first used as a patient record, but gradually more advanced functionalities such as «work flow» were used. Increasing system complexity made the clinicians vulnerable for potential errors and mistakes regarding saving and sending information. To prevent information «disappearing in the system», the system tailors became responsible for developing standards of use. The standardization work changed established work routines and at the same time generated knowledge about work processes, system functionalities, and user patterns that needed to be standardized.

Conclusion: The system tailors created connections between work processes and EPR. Integration of EPR in clinical work happened through the creation of such connections. As the system tailors are particularly influential in this respect, they should be used strategically in developing systems facilitating nursing work.

Keywords: Record, information technology, organization, qualitative study 


\section{Betingelser for vellykket integrering av elektronisk pasientjournal i klinisk arbeid}

Forfattere: Aud Obstfelder, Ann Therese Lotherington og Ann Britt Nilsen

\section{NøKKELORD}

- Journal

- Informasjonsteknologi

- Organisering

- Kvalitativ studie

\section{BAKGRUNN}

Utviklingen innen informasjonsog kommunikasjonsteknologi (IKT) går fort og forventningene er store $(1,2)$. I helsesektoren blir IKT ansett som et virkemiddel for samhandling, kvalitet og effektivitet. Både nasjonalt og internasjonalt ønsker sykepleiere seg elektroniske systemer som kan understøtte fagets særegenheter og arbeidsprosesser. For å få ønskene oppfylt vil de være med på å utvikle systemene (3-6).

Realisering av forventningene som IKT representerer er utfordrende $(2,7,8)$. Dette gjelder for IKT- systemer generelt og EPJ spesielt, som anses som grunnmuren for all elektronisk kommunikasjon og samhandling i helsesektoren (9). Vanlige forklaringer er at systemene ikke er tilpasset behovene, at informasjonen ikke er oppdatert, at det er for få datamaskiner i avdelingene, at påloggingsprosedyrer er tungvinte og at integrasjon mel- lom systemer er svak (10-14). Forslag til løsninger følger med beskrivelsene av utfordringene. Ofte nevnte løsningsforslag er brukerdrevet utvikling, opplæring, motivasjon for endring, økt standardisering og bedre integrering av systemer $(12,15,3)$. Det har imidlertid vært skrevet mindre om hva digitaliseringsog integrasjonsforsøkene egentlig dreier seg om (16). Hensikten med denne artikkelen er nettopp å bidra med kunnskap om dette. Datagrunnlaget er intervjuer med systemforvaltere $i$ et norsk sykehus og observasjoner av dem i arbeid. Alle hadde helsefaglig utdanning og erfaring og de fleste var sykepleiere. Vi ble oppmerksomme på denne gruppen ansatte $\mathrm{i}$ forbindelse med to forskningsprosjekter om IKT i sykehus som ble gjennomført i perioden 2004 og 2012. Artikkelen bygger på data fra to prosjekter som var finansiert av Norges forskningsråd. Prosjektene het «Space, Power and Communication. The dynamics of ICT in the Norwegian Health Care System» (Prosjektnummer: 163625) og «Ageing Healthcare Workers and ICT. Making Healtcare Workplaces Healthy for 50+» (Prosjektnummer 193606). I tidsperioden økte antall systemforvaltere fra to til åtte. De første ble ansatt av sykehusledelsen for å lede innføringen av sykepleiemodulen i det nye EPJ-systemet. Etter hvert som flere moduler og supplerende systemer ble lagt til og integrert i systemet, ble systemforvalterne involvert i oppgaver knyttet til økt standardisering i bruk av systemet.

For å belyse systemforvalternes arbeid knytter vi an til forskning som setter søkelys på hva som skjer når EPJ blir forsøkt integrert i arbeidsprosesser i sykehus (17-20). Forskningen gir et detaljert bilde av hvordan klinisk personell forbinder ulike funksjoner i EPJ med eta-

\section{Hva tilfører denne artikkelen?}

Artikkelen gir et innblikk i hvordan integrering av EPJ i klinisk helsearbeid kan skje og bli forstått.

\section{Mer om forfatterne:}

Aud Obstfelder er utdannet sykepleier med doktorgrad i sosiologi. Hun er førsteamanuensis ved det helsevitenskapelige fakultet, UiT. Ann Therese Lotherington har doktorgrad i statsvitenskap. Hun er professor ved Fakultet for samfunnsvitenskap, Universitetet i Nordland. Ann-Britt Nilsen er sykepleier med mastergrad i helsevitenskap og ansatt som prosjektleder i Helse Nord RHF. Kontakt: aud.obstfelderquit.no. 
blerte arbeidsrutiner. Den viser videre hvilke konsekvenser slike forbindelser har for hvordan arbeidsprosesser og samhandling i sykehus utfolder seg. Forskningen peker på hvordan EPJ i bruk knytter forbindelser mellom etablerte arbeidsprosesser og samhandlingsrutiner, endrer disse og frambringer helt nye. Denne forskningen er fundert i en forståelse av teknologi som sosiotekniske fenomener (21-22). Dette betyr at det alltid inngår verktøy, objekter, fakta og tek- arbeidsprosesser i sykehuset og funksjoner i EPJ blir knyttet sammen og hvilke konsekvenser dette har for arbeidsprosessene. Våre forskningsspørsmål er: 1) Hva gjør systemforvalterne for å integrere EPJ med arbeidsprosesser i sykehuset? 2) Hva slags type arbeid utfører de? og 3) Hva er konsekvensene?

\section{MATERIALE OG METODE}

De to forskningsprosjektene som datamaterialet er hentet fra hadde etnografisk design (23).

\section{Systemet er sykehuset i miniatyr.}

nologier i sosiale praksiser. Man kan ikke forstå eller studere praksisene uten dem. Omvendt kan vi si at praksisene er effekter av spesifikke forbindelser mellom sosiale og tekniske forhold. Det er forbindelsene som frambringer arbeidsprosesser, samhandling, men også fakta, objekter og subjekter. Følgelig; dersom de sosiotekniske forbindelsene endres, så endres også praksisene. Dette gjelder også for sykepleiepraksiser (21).

I artikkelen analyserer vi systemforvalternes arbeid. Innføring av EPJ er komplekse situasjoner hvor ny teknologi integreres med etablerte sosiotekniske praksiser. For at sykepleiere skal kunne bruke EPJ strategisk i kunnskaps- og kompetanseutvikling relatert til egen praksis (6), må kompleksiteten erkjennes og håndteres (16). Med artikkelen ønsker vi å bidra til oppmerksomhet og forståelse for noen sider av denne kompleksiteten. Vi beskriver ikke spesifikke funksjoner i EPJ og hvilke effekter disse har på sykepleiernes arbeidsprosesser og samhandling, men hvordan etablerte
Begge studiene var godkjent av NSD. I datainnsamlingen brukte vi individuelle intervjuer og fokusgruppeintervjuer med klinikere, ledere, systemforvaltere og IKT-brukerstøtte. I tillegg observerte vi systemforvaltere i arbeid, tok feltnotater og analyserte relevante interne dokumenter.

Data brukt i denne artikkelen er hentet fra individuelle intervjuer og fokusgruppeintervjuer med systemforvaltere, ansatte fra IKT-brukerstøtte og observasjon av systemforvaltere $i$ arbeid. Intervjudata ble analysert $\mathrm{i}$ henhold til en stegvis deduktiv-induktiv metode (24). Metoden kombinerer sensitivitet for data med ambisjoner om å fortolke data i lys av teoretiske perspektiver. Transkripsjoner av intervjuer ble lest og utsagn som var relevante for problemstillingen ble kodet. Etter at transkripsjonene var lest og kodet ble kodene samlet i to hovedgrupper: 1) Fra journalsystem til system for informasjonsflyt, 2) Utvikling av prosedyrer. Hovedgruppene utgjør tema som strukturerer resultatdelen av undersøkelsen. Feltnotatene ble brukt for å justere kodene og bekrefte de endelige temaene. Alle navn som er brukt i tilknytning til sitatene er fiktive av hensyn til informantenes anonymitet.

\section{RESULTATER \\ Informasjonsflyt}

Sykehuset innførte ny EPJ i 2004 og de to første systemforvalterne ble ansatt. De skulle hjelpe sykepleiere, leger og andre brukere av systemet til å utvikle gode vaner knyttet til pålogging, informasjonssikkerhet og dokumentasjon. I tillegg skulle de gi tilbakemeldinger til leverandøren og IKT-avdelingen om feil i systemet, assistere ved testing av oppgraderinger og ved innføring av ny funksjonalitet.

Fra 2006 til 2010 ble flere moduler lagt til og supplerende informasjonssystemer integrert. Antall systemforvaltere økte fra to til åtte. I samme tidsperiode ble sykehuset slått sammen med flere mindre lokalsykehus og en felles EPJ-database utviklet. Antall brukerkontoer økte fra 400 til 7000. Systemet, som hadde blitt introdusert som en enkel EPJ, hadde utviklet seg til en omfattende informasjonsinfrastruktur (25). Samhandlingsrutiner som tidligere var støttet av andre elektroniske informasjonssystemer, papirbaserte skjema og muntlig kommunikasjon, skulle nå gjøres i EPJ. Eksempler på dette var rekvirering av interne tjenester, skriving av epikriser og brev, registrering og overflytting av pasienter mellom avdelinger. Systemet var ikke lenger kun et system for dokumentasjon av klinisk arbeid, men også et system for informasjonshåndtering og aktivitetsregistrering. En systemforvalter beskriver det slik i et intervju: «Systemet er sykehuset i miniatyr». 
Henvendelsene fra klinikerne endret samtidig karakter. I starten dreide det seg om praktiske spørsmål som for eksempel pålogging, men etter hvert handlet det mer om hvordan finne og sende informasjon i systemet. En annen systemforvalter uttalte: «EPJ gir oversikt og forenkler, men for noen klinikere kan det være vanskelig å finne informasjon".

En medarbeider innenfor IKT-brukerstøtte sa følgende i et fokusgruppeintervju: «De er veldig redde for å miste pasientene [i systemet]. De forstår ikke hva som skjer med informasjonen etter at de har trykket på knappen. Dette skaper usikkerhet».

Systemforvalterne fikk også henvendelser fra helsesekretærene og lederne. De kunne fortelle om dokumenter i systemet som ikke var åpnet, om pasientlister som ikke var oppdatert og om driftsrapporter som ikke stemte med manuelle lister.

\section{Utvikling av prosedyrer}

Endringene i henvendelsene ble oppfattet av systemforvalterne som manglende forståelse for hvordan systemet var satt opp. Klinikerne håndterte funksjoner knyttet til dokumentasjon av klinisk arbeid, men utførelser knyttet til sending av informasjon i systemet og overflytting av pasienter mellom enheter, skapte utfordringer. Flere var ikke klar over at informasjon måtte registreres i henhold til oppsettet for at den skulle flyte «riktig». Behovet for å standardisere bruken ble innlysende:

«Vi er ledere av systemet. Vi må lage reglene for hvordan det skal fungere i sykehuset» uttalte en systemforvalter $i$ et fokusgruppeintervju.

$\AA$ utvikle regler for hvordan systemet skulle fungere var et gjennomgående trekk ved sys- temforvalternes arbeid. Dette ble intensivert i forbindelse med oppgraderinger av systemet og ved innføring av felles EPJ-database.

Et særtrekk ved arbeidet med å utvikle prosedyrer var detaljerte diskusjoner mellom systemforvalterne, klinisk personell og ledelsen om hvordan prosedyrene skulle se ut. I diskusjonene ble kliniske og administrative rutiner og funksjoner i EPJ sett i sammenheng. For eksempel ønsket ledelsen bedre oversikt over pasientenes bevegelse mellom avdelingene $\mathrm{i}$ "sanntid» og oppdaterte aktivitetsrapporter. En måte å få slik oversikt på var å utnytte mulighetene i Sengepostlisten (26). Sengepostlisten er en funksjon i EPJ som viser hvilke pasienter som er registrert på en sengepost, og som gjør det enklere for klinisk personell å finne frem til informasjon om dem. Listen oppdateres automatisk når nye pasienter registreres. For å få oversikt over pasientene, riktige aktivitetsrapporter og tilgang til journalinformasjon, var rett registrering avgjørende. Dette var imidlertid ikke enkelt da det forutsatte god kjennskap til systemets oppsett og navn på organisasjonsenheter som avdelinger og sengeposter. Det var sykepleierne som gjorde flest feilregistreringer og etter hvert ble det bestemt at helsesekretærene skulle gjøre registreringene. Beslutningen innbefattet opprettelsen av en døgnkontinuerlig kontortjeneste.

Det vi ser her er at dersom mulighetene i systemet skulle bli utnyttet, måtte disse bli integrert i arbeidsprosesser og samhandlingsrutiner på bestemte måter. For å få oversikt over pasientflyten $\mathrm{i}$ «sanntid» ble arbeidsprosesser knyttet sammen og gjennom dette endret. Dette vises ved at sykepleiernes tilgang til journal- informasjon, vaktordninger for helsesekretærene og forhandlinger om oppgavefordeling mellom sykepleierne og sekretærene, ble tatt opp til diskusjon og sett $\mathrm{i}$ sammenheng med hverandre. Teknologi, helsepersonell, vaktordning og ansvar ble altså vevd sammen og nye sosiotekniske praksiser ble skapt.

Et annet gjentakende diskusjonstema var hvordan funksjoner i systemet skulle begrepsfestes slik at de ga assosiasjoner til «rett bruk». For eksempel ble det i forbindelse med innføring av felles EPJ-database behov for å endre navn på arbeidsgruppene i systemet. Informasjonsflyten i systemet var organisert omkring slike arbeidsgrupper som teknisk sett var elektroniske postkasser. Før sammenslåingen hadde sykehusene brukt det samme EPJ-systemet, men arbeidsgruppene var merket forskjellig. Dette hadde medført betydelig feilsending av informasjon og dokumenter hadde blitt liggende uåpnet i arbeidsgruppene. Med felles EPJ-database ble det nødvendig å benytte en konsistent logikk i navngivingen. Diskusjonen dreide seg om arbeidsgruppene skulle merkes etter geografisk tilhørighet eller arbeidsoppgaver. En systemforvalter er gjengitt slik i et internt dokument: "Alle arbeidsgruppene må ha et prefix som inneholder avdelingens kortnavn (for eksempel MED). Dersom en arbeidsgruppe er koblet til en bestemt post/seksjon skal kortnavnet til posten/seksjonen kobles på (for eksempel KAR). Etter dette skal funksjonen beskrives (for eksempel Tilsyn). Hvilken geografiske enhet arbeidsgruppen er tilknyttet skal beskrives også (for eksempel Lillevik, Storvik og så videre). Eksempel på arbeidsgruppenavn: MED, KAR, Tilsyn, Lillevik». 
Informasjonsformidling mellom avdelingene er etablerte praksiser som er organisert omkring ulike kliniske problemområder. Praksisene er utviklet over tid og læres gjennom erfaring. Praksisene genererer beslutninger om behandlingsforløp og aktivitetsrekkefølger som er støttet av informasjon om pasienter og øvrige forhold i avdelingene. Informasjonen formidles via samtaler, sanseinntrykk, papirbaserte og elektroniske skjemaer og dokumenter $(19,26,27)$. andre arbeidsprosesser og samhandlingsrutiner ble diffust. Hva som hørte til systemet og hva som hørte til klinikken ble vanskelig å skille fra hverandre. Det uklare skillet ble for eksempel aktualisert når systemforvalterne forsøkte å finne ut hvorfor enkelte informasjonselementer ikke dukket opp på forventet sted i systemet. Ulike forklaringer ble brukt: Prosedyren kunne være uklar, legene visste ikke hvilke arbeidsgrupper de hadde tilgang til, systemet kunne være satt opp feil eller det kunne

\section{Praksisene er utviklet over tid og læres gjennom erfaring.}

Diskusjonene vedrørende navn på arbeidsgruppene representerte endringer $\mathrm{i}$ samarbeidsrutiner mellom avdelingene og spesialitetene på sykehuset. For klinikerne handlet endringer i navn om endringer av arbeidsvaner og dermed ble diskusjoner om navnene utfordrende.

Et annet trekk ved diskusjonene var at de bidro til nye ideer om hvordan EPJ kunne brukes og måtte settes opp for at ideene skulle bli realisert. For eksempel ble det lansert en idé om å etablere et felles virtuelt ventelistekontor på tvers av sykehusene. Gevinsten skulle være bedre utnyttelse av behandlingskapasiteten ved sykehuset. Da ideen skulle realiseres kom det frem at flere avdelinger ikke hadde startet arbeidet med å tilpasse driften til et felles ventelistekontor. EPJ hadde derfor ikke blitt satt opp for å støtte et slikt samarbeid. Dette resulterte i at ventelister ble håndtert som før, uten tanke på utnyttelse av den totale behandlings- og arbeidskapasiteten.

Et siste trekk ved diskusjonene var at forskjellen mellom EPJ og foreligge tekniske feil i systemet. For å holde EPJ og arbeidsprosessene fra hverandre brukte systemforvalterne begrepene den «virtuelle organisasjonen» og den «administrative organisasjonen». Dette utdyper vi i det følgende:

\section{DISKUSJON \\ Praktisk arbeid}

Gjennom vårt forskningsarbeid med systemforvalterne ble det etter hvert tydelig at systemforvaltning hadde karakter av å være praktisk arbeid. Praktisk arbeid i sykehus foregår hele døgnet $o g$ er fordelt på ulike organisatoriske enheter og spesialiteter. Aktiviteter knyttet til behandling og pleie av pasienter er stykket opp og fordelt mellom ulike yrker (27). Sykepleiere har en sentral rolle i å knytte detaljene sammen til velfungerende helheter. De sørger for kontinuitet og samordning av aktivitetene. Viktige premisser for slikt «forløpsarbeid» er kunnskap om lokale forhold og artikuleringsarbeid (28). Artikuleringsarbeid er «limet» som holder de komplekse arbeidsprosessene sammen.

En slik arbeidsform tok sys- temforvalterne med seg inn i arbeidet med å utvikle prosedyrer. De diskuterte hvordan systemet skulle brukes for å få arbeidsoppgaver som var utført av ulike klinikere til å henge sammen i forutsigbare handlingskjeder. Slik sett er utvikling av prosedyrer artikuleringsarbeid og en form for praktisk arbeid.

Systemforvalterne hadde ikke formell utdanning innen systemforvaltning, men utviklet handlingskompetanse gjennom å lære klinikerne å bruke EPJ, og gjennom diskusjoner med systemleverandøren, IKT-brukerstøtte og andre relevante instanser. Ved å jobbe med problemstillinger knyttet til bruk av EPJ fikk de oversikt over de ulike funksjonalitetene i systemet. For eksempel dreide dette seg om hvilke funksjonaliteter som hadde forbedringspotensial, eller om oppsettet av EPJ var intuitivt nok. Gjennom arbeidet med å utvikle prosedyrer fikk systemforvalterne oversikt over hvordan avdelingene organiserte arbeidet. De fikk også oversikt over hvilke arbeidsoppgaver ulike grupper klinikere regnet som sine og hvilke de regnet som andres. Systemforvalterne fikk også oversikt over klinikernes vaner og holdninger knyttet til bruk av journalen. Ved å tilegne seg kjennskap til systemet, brukerne og sykehusarbeidet, fikk systemforvalterne ideer om arbeidsprosesser som kunne støttes av EPJ. De ble i stand til å korrigere bruk og luke ut uheldige bruksrutiner som var i ferd med å utvikle seg. Dermed fikk de stor innflytelse på det daglige arbeidet i sykehuset.

\section{Politiske aktører}

Konsekvensen av det praktiske arbeidet systemforvaltere utfører er at de kan betraktes som politiske aktører. EPJ tilbyr standarder for dokumentasjon av klinisk 
arbeid og for informasjonsflyt $\mathrm{i}$ sykehuset. Standardene legger føringer for hva som kan skrives hvor og av hvem. Vanligvis posisjoneres legene som sentrale beslutningstakere og de andre helseprofesjonene som utøvere av legenes forordninger og som informasjonsformidlere (17). Følgelig har EPJ kapasitet til å skape struktur i arbeidet og å bygge relasjoner mellom profesjonene.

Standardene som er skrevet inn i EPJ's arkitektur skaper imidlertid ikke struktur, kunnskap og relasjoner i seg selv. Standardenes generative egenskaper blir aktualisert først når de blir integrert i praksis, det vil si når standardene $\mathrm{i} \mathrm{EPJ}$ møter sykehusarbeidets komplekse og dynamiske karakter. Her kommer systemforvalterne inn i bildet. Gjennom arbeidet med å utvikle prosedyrer, ble standardene i EPJ og kompleksiteten i sykehusorganisasjonen koblet sammen. Prosedyrene representerte forventninger om hva klinikerne skulle gjøre i ulike situasjoner. Dersom prosedyrene ble brukt, ble spesifikke aktivitets- og handlingssammenhenger satt i bevegelse, kunnskap ble brakt frem og profesjonsrelasjoner utfordret.

Ved å utvikle prosedyrer fikk systemforvalterne stor innflytelse på utforming av arbeidspraksiser og på oppgavefordeling mellom helseprofesjonene. Systemforvalterne ble på denne måten utøvere av praktisk politikk (25) med betydelig innflytelse på det daglige arbeidet i klinikken. Integrering av EPJ $\mathrm{i}$ arbeidsprosesser og samhandlingsrutiner ble med andre ord realisert gjennom arbeidet med å utvikle prosedyrer.

\section{Produsenter av fakta}

Et resultat av det praktiske systemforvaltningsarbeidet var produksjon av fakta om sykehusorganisasjonen. Diskusjonene rundt prosedyreutvikling dreide seg om hvordan arbeidsprosesser og samhandlingsrutiner i sykehuset skulle organiseres, og det ble samtidig skapt nye innsikter om så vel arbeidsprosessene som EPJ. I diskusjonene ble nye områder av arbeidsprosesser som ikke var støttet av EPJ kontinuerlig aktualisert. Innsiktene ble brakt fram i og med diskusjonene. Det var imidlertid ikke arbeidsprosessene eller EPJ i seg selv som ble aktualisert. I etablering av felles ventelistekontor ble dette analytiske poenget tydelig. Enkelte seksjoner hadde ikke satt $i$ verk nødvendige tilpasninger verken $\mathrm{i}$ arbeidsmåter eller i EPJ. Både seksjonene og EPJ framsto med dette som realiteter som måtte forbedres. Realitetene, altså ikke godt nok oppsett av systemet, gammeldagse rutiner for håndtering av ventelister og endringsuvillighet, ble brakt frem i et samspill mellom systemforvalterne, EPJ og klinikere. Like fullt, effektene av samspillet framsto som realiteter som systemforvalterne måtte forholde seg til. Når egen-

\section{Innholdet i prosedyrene blir til gjennom diskusjonene.}

skapene først var løftet frem kunne de ikke bli ignorert.

Et siste forhold som ble aktualisert var det uklare skillet mellom hva som var arbeidsprosesser og hva som var EPJ. Systemforvalterne snakket noen ganger om EPJ og arbeidsprosessene som to forskjellige ting og noen ganger som det samme. Dette kan man forstå som et uttrykk for at EPJ var blitt en «bestanddel» i sosiotekniske forbindelser. Det var forbindelsene som brakte frem mulighetene for handling og strukturer og ikke systemet eller sykehusarbeidet $\mathrm{i}$ seg selv. EPJ og arbeidsprosesser var blitt knyttet sammen på bestemte måter og det var sammenknytningene som brakte frem aktiviteter, strukturer og egenskaper ved situasjoner og personer. EPJ var blitt et sosioteknisk system der systemforvalterne utgjorde et avgjørende element i arbeidet med å knytte samme den «virtuelle» og den «administrative» organisasjonen.

\section{KONKLUSJON}

I artikkelen har vi gitt et innblikk i hvordan integrering av EPJ i klinisk arbeid kan skje og bli forstått. Vi har ikke fokusert på hvordan enkeltfaktorer som brukervennlighet, klassifikasjonssystemer eller opplæring kan bidra til dette, men hvordan «de små og hverdagslige tingene som ofte blir tatt for gitt» (8) gjør det. Det er de egentlige integreringsforsøkene vi har vært opptatt av.

Sykepleiere som ønsker å bruke IKT til å fremme sykepleiefaglige verdier, må ha

kunnskap om hvordan slik integrering kan gjøres. De må være villige til å gå inn i diskusjoner med systemforvaltere om hvordan funksjoner i EPJ kan brukes for å forme arbeidsprosesser og samhandling på bestemte måter. Det er i diskusjonene at utfordringer og muligheter som EPJ representerer kan bli belyst og hvor grunnlaget for beslutninger om prosedyrene blir lagt. Syke- 
pleiere som ønsker at systemene skal støtte sykepleiefaglige verdier må ta del i diskusjonene. Innholdet i prosedyrene blir til gjennom diskusjonene. For å få innflytelse må sykepleiere delta.

Kunnskapsbasert utvikling og implementering av IKT er et sentralt tema i nasjonal og internasjonal litteratur. Man er enige om at det er behov for helsepersonell med samme kompetanse som systemforvalterne, til å lede og utføre målrettet integrasjons- arbeid (5,6,29-31). I artikkelen har vi vist at integrasjonsarbeid er praktisk arbeid som både forutsetter og frambringer kunnskap om utøvelse og organisering av klinisk arbeid og IKT.

\section{REFERANSER}

1. Forsknings- og administrasjonsdepartementet. eNorge 2009 - Det digitale spranget. Tilgjengelig fra: http://www. regjeringen.no/nb/dep/fad/tema/iktpolitikk/enorge-2009.html?id=439499 (Nedlastet 17.08.2013).

2. Helse- og omsorgsdepartementet. Samhandlingsreformen. St.meld. 47 (2008-2009)

3. While A, \& Dewsbury G. Nursing and information and communication technology (ICT): a discussion of trends and future directions. Int J Nurs Stud. 2011: 48:1302-10.

4. Barry J, Hardiker N. Advancing Nursing Practice Through Social Media: A Global Perspective, OJIN. 17;3 Manuscript 5.

5. Royal College of Nursing. Positioning nursing in a digital world. RCN eHealth survey 2012 report. 2013.

6. Norsk sykepleieforbund. NSFs Strategi - eHelse, 2013-2016.

7. Greenhalgh T, Potts H, Wong G, Bark $P$, Swinglehurst $D$. Tensions and paradoxes in electronic patient record research A systematic literature review using the meta-narrative method. Milbank Q. 2009;87:729-788.

8. Aanestad M. IKT for bedre samhandling: Løsning eller problem. I: Aanestad M., Olaussen I (red). IKT og samhandling helsesektoren. Digitale lappetepper eller sømløs integrasjon? Tapir Akademiske forlag. Trondheim. 2010.

9. Bakke KA. Sykepleiere intensiverer IKT-satsingen. Dagens medisin, 19.03.13 Tilgjengelig fra: http://www.dagensmedisin.no/nyheter/sykepleierneintensiverer-ikt-satsingen/. (Nedlastet 22.12.2013)

10. Berg M. Implementing information systems in health care organizations myth and challenges. Int. J. Med. Inf 2001;64(2-3):143-156

11. Vikkels $ø$ S. Sublte Redistribution of Work, Attention and Risks: Electronic Patient Records and Organisational Consequences. SJIC. 2005;17: Article 10 12. Aarts J, Callen JL, Coiera EW, Westbrook, Jl. Information technology in health care: Socio-technical approaches. IJMA; 79:389-390
13. Stevenson JE, Nilsson, GC, Petersson, GJ, Johansson, PE. Nurses experience of using electronic patient records in everyday practice in acute/inpatient ward setting: a literature review. Health Inform J. 2010; 16: 63-72.

14. Cunningham L, Kennedy J, NwolisaF, Callard L, Wike C. Patients not paperwork: Bureucracy affecting nurses in the NHS. Coventry: NHS Institute for Innovation and Improvement. 2012. Tilgjengelig fra: http://www.institute.nhs.uk/ quality and value/productivity series/ the_productive_series.html. (Nedlastet 22.12.2013)

15. Clegg C, Ellis, B, Wyatt JC, Elliott B, Sinclair M, Wastell DA. Manifesto for a socio-technical approach to NHS and social care, IT-enable business change to deliver effective high quality health and social care for all. Leeds: UK Faculty of Health Informatics, University of Leeds. 2010. Tilgjengelig fra: http://www.bcs. org/upload/pdf/st-manifesto-260810.pdf. (nedlastet 22.12.2013)

16. Aanestad, M. Fra «sømløs integrasjon» til «integrasjonens sømmer». I: Aanestad M., Olaussen I (red). IKT og samhandling i helsesektoren. Digitale lappetepper eller sømløs integrasjon? Tapir Akademiske forlag. Trondheim. 2010

17. Berg M, Bowker G. The Multiple Body of Medical record. Sociol Quart. 1997; 38: 513-537.

18. Hartswood M, Procter R, Rouncefield M, Slack R. Making a Case in MedicalWork: Implications for the Electronic Patient Record. Comput. Support. Coop. Work. 2003;12:241-266.

19. Halford S, Obstfelder A, Lotherington AT. Changing the record: the interprofessional, subjective and embodied effects of electronic patient record. New. Tech. Work. Employ. 2010; 25: 210-222. 20. Moser, I. Fra flyt til fluiditet: om metaforer for og modeller av informasjon i helsefaglige praksiser og e-helseplaner. I: Aanestad M., Olaussen I (red). IKT og samhandling i helsesektoren. Digitale lappetepper eller sømløs integrasjon? Tapir Akademiske forlag. Trondheim. 2010

21. Sandelowski M. Devices \& Desires.
Gender, Technology, and American Nursing. The University of North Carolina Press: Chapel Hill. 2000.

22. Aanestad M, Olaussen I. Tverrfaglig teknologiforskning. I: Aanestad M. Olaussen I (red). IKT og samhandling i helsesektoren. Digitale lappetepper eller sømløs integrasjon? Tapir Akademiske forlag. Trondheim. 2010.

23. Bloor M. The Ethnography of Healh and Medicine. I: Atkinson P, Coffey A, Delamont S, Lofland J, Lofland L. (eds). Handbook of Ethnography. Sage Publications. London. 2001

24. Tjora A. Kvalitative forskningsmetoder i praksis. Gyldendal akademiske: Oslo. 2010

25. Bowker J, Star SL. How things (actor-net) work: Classification, magic and the ubiquity of standards. Philosophia. 1998; 25:1995-220.

26. Nilsen, A-B. Sengepostlisten: En aktør i mange nettverk: om implementering av EPJ og hvilken betydning dette får for organisering av praktisk pasientarbeid. Masteroppgave. Institutt for helse-og omsorgsfag. Det helsevitenskapelige fakultet, Universitetet Tromsø. 2011

27. Olsvold N. Sykehusarbeidets organisering og profesjonenes arbeids-og ansvarspraksis. I Tjora A. (red) Helsesosiologi. Gyldendal akademiske. Oslo. 2012

28. Strauss A, Fagerhaugh B, Wiener S, Wiener C. Social organization of medical work. 1th ed. Chicago. University of Chicago Press; 1985

29. Winter AF, Ammenwerth $E$, Bott OJ, Brigl B, Buchauer A, Gräber S, Grant A Häber A, Hasselbring W, Haux R, Heinrich A, Janssen H, Kock L, Penger OS, Prokosch H-U, Terstappen A, Winter A. Strategic information management plans: the basis for systematic information management in hospitals. IJMI. 2001; 64: 99-109.

30. Hersh W. Health Care Information Technology. Progress and Barriers. JAMA. 2004; 292: 2255-2274

31. Amatayakul MK. Electronic Health Records. A Practical Guide for Professionals and Organizations. AHIMA. Illinois. 2004. 